\title{
Embracing Ambiguity: A Framework for Promoting Iterative Design Think- ing Approaches in Engineering and Design Curricula
}

\section{Annie Abell, Ohio State University}

Annie Abell is an Assistant Professor of Practice at The Ohio State University in the Department of Mechanical \& Aerospace Engineering. Abell received her BS in Mechanical Engineering from Valparaiso University and a MFA in Design Research \& Development from The Ohio State University with an emphasis on Industrial Design. She teaches project-based, product design courses to senior-level and graduate engineering students, as well as an interdisciplinary product development course for entrepreneurship students who come from across OSU.

\section{Kelly DeVore, Columbus College of Art and Design}

Kelly DeVore is an Assistant Professor and Chair of Interior Design at The Columbus College of Art and Design. DeVore received her Bachelors of Architecture from Iowa State University and a MFA Design Research \& Development from The Ohio State University with an emphasis on Higher Education. DeVore currently teaches interior design senior capstone studios, has developed a course on design for social change, and mentors graduate students in the new MDes program in Integrative Design. 


\title{
Embracing Ambiguity: A Framework for Promoting Iterative Design Thinking Approaches in Open-Ended Engineering and Design Curricula
}

\author{
Introduction \\ Engineering students and design students approach projects with different mindsets. However, despite \\ their differences, students in design and engineering often exhibit similar behaviors throughout the design \\ process with a proclivity to quickly converge on a final solution, often motivated by an attempt to escape \\ the ambiguous user-research phase of design. The authors believe that as instructors acknowledge and \\ encourage students to explore and embrace open-ended projects, the students will have a higher \\ likelihood of shedding the fear and anxiety that often comes with these unknown project outcomes.
}

This paper will explore successful engineering and design pedagogy case studies, taken from coursework and curricula at Ohio State University and at Columbus College of Art \& Design. These stories and challenges will be explained to highlight what can emerge from creating curricula around open-ended design pedagogy, which serves to mimic real world, often 'wicked' scenarios. By describing engineering and design programs doing similar pedagogical activities, the authors will reflect on their own classroom experiences, discuss lessons learned, and propose a framework that instructors can call upon to encourage students to embrace ambiguity, thus becoming more agile and resilient in the future.

Each author has taught the case study courses for several years and each has noted the pattern of pedagogical challenges that have come up while conducting open-ended, ambiguous design projects. These patterns were the motivation for exploring a framework that could better support learning outcomes and further to develop the students' abilities to iterate and think through critical problems and ambiguous scenarios without getting caught on initial design solutions. These steps include ideas for: collaboration, overwhelming, empathizing, reflecting, mitigating, acknowledging, and empathizing into classroom activities. The following is a series of examples and contextualization of these terms. This framework, which encompasses steps to contextualizing ambiguity, could be applied by other instructors in a range of course settings across engineering and design disciplines.

\section{Benchmarking the Design Process and Design Thinking}

The pedagogical differences between engineering and design, specifically surrounding questions of ambiguity, are rooted in the terminology used to describe design thinking and design process. First, the types of students that are enrolled in engineering courses vs. design courses are different; differences exist in approach to problem solving, likely due to the fundamental and cultural differences of each discipline. It is true that the design processes employed by both disciplines do have similarities, however there are fundamental differences in the approach and semantic differences in the discussion of the processes in each discipline. Furthermore, the two fields approach design thinking differently. In this section, the authors describe the differences in approach and process in a variety of contexts in order to review these relevant practices and understand the context in which the authors intend to use this terminology.

Design thinking is a popular phrase that has gained traction in business, education, and industry, and is now used by many disciplines in these fields. At its core, design thinking is a problem-solving methodology that borrows from the tools and mindsets of designers in order to allow problem solvers to reframe their view of a challenge from a new perspective, with the goal of creating innovative, humancentered solutions. ${ }^{1,2}$ The phrase design thinking was originally coined by Tim Brown, the CEO of IDEO. ${ }^{3}$ Brown writes in his 2009 book Change by Design, 


\begin{abstract}
"Design thinking taps into capacities we all have but that are overlooked by more conventional problem-solving practices. It is not only humancentered; it is deeply human in and of itself. Design thinking relies on our ability to be intuitive, to recognise patterns, to construct ideas that have emotional meaning as well as functionality, to express ourselves in media other than words or symbols." 4
\end{abstract}

A core principle of design thinking is to maximize innovation through iteration. The principle dictates that those applying design thinking methodology will repeatedly test out ideas, fail early and often, and "spend a surprising amount of time not knowing the answer to the challenge at hand". The act of producing and testing out many ideas is at the heart of innovation. As Linus Pauling said, "If you want to have good ideas you must have many ideas. Most of them will be wrong, and what you have to learn is which ones to throw away." 6

To many, especially in STEM fields, design is often thought of as being a 'late-stage add-on' making already developed ideas more desirable for customers or clients. However, the design is a process that embodies the act of breaking a project or task down into manageable actions or steps in order to solve a variety of problems. This applies to many fields in engineering, architecture, design (commercial interior design, product design, graphic design), and the sciences alike. Traditionally, students in both engineering and design were taught to repeat these steps or actions until proficiency is achieved. The outcome was always (quite often) fixed and had a set goal, not articulated by the user necessarily, but by the designer or engineer.

Many descriptions or models of design processes that incorporate design thinking are general descriptions or models, so that the process could be applied to any discipline, whether it is a classic design discipline (e.g., product design, interior design, etc.) or another discipline that engages in problem-solving activities (e.g., engineering disciplines, city planning, architecture, etc.). The authors will provide a review of several representative design processes from various disciplines to familiarize the reader with the similarities, differences, and notable distinctions among the various processes.

In architecture and the built environment, the design process follows standard steps to align with the building industry. The AIA (American Institute of Architects) ${ }^{7}$ defines the design process in terms of basic services during the following phases:

1. Schematic Design (SD)

2. Design Development (DD)

3. Construction Document (CD)

4. Bid or Negotiation (BN)

5. Construction Administration (CA)

Industrial and product design follow similar paths in a more formalized process model. A model from Milton $\&$ Rodgers ${ }^{8}$ presents a process that would be familiar and representative to the product design community:

1. Research

- background stage

- exploratory stage

2. The brief

- identifying customer needs

- completing the Product Design Specification (PDS)

3. Concept design

- generation of ideas 
- sketches, drawings, and renderings

- evaluation of concept

4. Design development

- technical drawings

- prototypes

5. Detail Design

- exploring materials

- exploring manufacturing techniques

- testing and refinement

6. Production

- marketing

- supply

- disposal

Many steps here run parallel to those in the design processes of other disciplines, but of note here is that the product designers engage in researching, exploring, and defining the problem areas and identifying needs in addition to being involved in the more technical aspects such as creating technical drawings, building prototypes, evaluating prototypes, and manufacturing.

This linear design process works well in professional practice, but within each design phase, there is iteration, dialogue, and ambiguity. As Benzenberg notes in her research on Design Process, "Since most projects have a starting point and a finished project, it is tempting to try to describe this process in a linear or sequential fashion. However, an iterative or cyclical process may more accurately describe the thought process that creative individuals go through to produce a solution to a design problem." ${ }^{9}$ Moreover, noted design researcher Liz Sanders writes,

"Formerly called "pre-design", the front end describes the many activities that take place in order to inform and inspire the exploration of open-ended questions such as "how can we improve the quality of life for people living with a chronic illness?" or "what is the next big thing in family leisure time?" The front end is often referred to as "fuzzy" because of the ambiguity and chaotic nature that characterize it. In the fuzzy front end, it is often not known whether the deliverable of the design process will be a product, a service, an interface, a building, etc. ...The fuzzy front end is followed by the traditional design process where the resulting ideas for product, service, interface, etc. are developed first into concepts, and then into prototypes that are refined on the basis of the feedback of future users. "10 


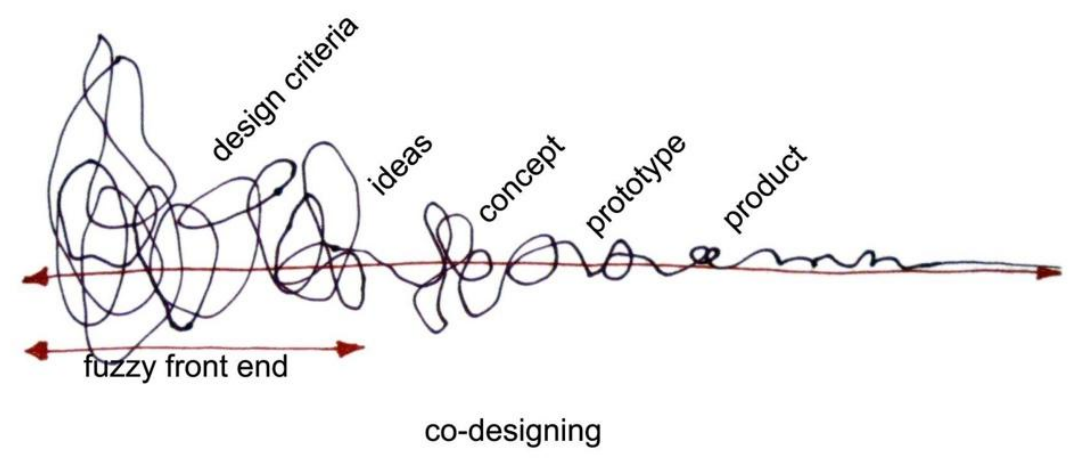

Figure 1: Diagram, showing Sanders' Co-Design Process

Here again, we see a linear process but instead of one continual line, the process loops and circles back to include reflection - going back to rethink and reformulate opinions based on lessons learned. In Sanders' process model, she notes of the more typical design process phases of: 1) Idea 2) Concept 3) Prototype 4) Produce/Finalize, however she additionally adds the components in the beginning - the nebulous "fuzzy" front end and 'wicked problem' area of design and development when the outcomes are more unclear. ${ }^{10}$

\section{Engineering Design Process}

Like the disciplines in the design field, the engineering field also has its own variations on the approaches to the design process; there is agreement within the community about what the engineering design process encompasses at a high-level, however many variations exist.

Engineering students across the nation are familiar with the Engineering Design Process, as it is an influential process in industry and thus a notable part of any accredited engineering curriculum, as many readers will know. ABET (The Accreditation Board for Engineering and Technology) has articulated seven student learning outcomes that are required of any accredited engineering curriculum, the second of which is, "An ability to apply both analysis and synthesis in the engineering design process, resulting in designs that meet desired needs." 11 Of note in this description is that the focus is on providing a solution but there is no mention of identifying the problem which is to be solved.

Though there is general consensus in the professional engineering community on what the Engineering Design Process encompasses at a high level, there are many variations in defining the steps that comprise the Engineering Design Process. The various interpretations are all rooted in providing a methodology for solving problems. Authors Pahl et. al ${ }^{12}$ state that any design methodology must:

- allow a problem-directed approach; i.e. it must be applicable to every type of design activity, no matter which specialist field it involves

- foster inventiveness and understanding; i.e. facilitate the search for optimum solutions

- be compatible with the concepts, methods and findings of other disciplines

- not rely on finding solutions by chance

- facilitate the application of known solutions to related tasks 
A subset of the Engineering Design Process encompasses versions dedicated to product design and development. Here several processes will be reviewed and similarities \& differences discussed.

The textbook Engineering Design \& Rapid Prototyping by Kamrani \& $\mathrm{Nasr}^{13}$ approaches the engineering product design with a five-step process:

1. Identify the Need/Problem

2. Research the Need/Problem

3. Develop Possible Solutions

4. Select Best Possible Solution

5. Construct a Prototype

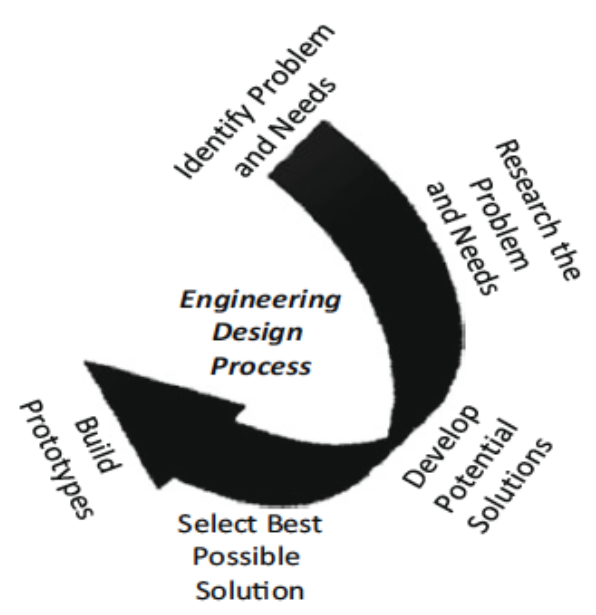

Figure 2: Engineering Design Process by Kamrani \& Nasr

Of note here is that in discussions Step 1 ('Identify problem and needs') the text states, "This step is not always realized by engineers. Problems are typically identified by the market and customers and then passed on to the engineering group to search and develop solutions." ${ }^{13}$ Additionally, Kamrani \& Nasr view the design process as a somewhat linear process; discussion of iteration only occurs in the context of the necessity of repeating the entire process if a final design does not meet performance criteria. Based on the author's experiences in industry and the classroom, this process model by Kamrani and Nasr is a classic and common representation of the view of the Engineering Design Process by those in the field of Mechanical Engineering.

The text 'Design Engineering' ${ }^{14}$ takes a slightly different approach to the general Engineering Design Process, which uses somewhat different terminology due to the authors being from the UK.

1. Concept [market research, identifying new technology]

2. Scheme Design [solution generation]

3. Detail Design [determining details of chosen design, testing]

4. Manufacture [design for assembly, design for manufacture, fabrication]

5. Post Production [distribution, sales] 


\begin{tabular}{|c|c|c|c|c|}
\hline Concept & $\begin{array}{l}\text { Scheme } \\
\text { design }\end{array}$ & $\begin{array}{l}\text { Detail } \\
\text { design }\end{array}$ & Manufacture & $\begin{array}{c}\text { Post- } \\
\text { production }\end{array}$ \\
\hline $\begin{array}{l}\text { New technology } \\
\text { Market needs } \\
\text { Market research } \\
\text { Specifications } \\
\text { Quality }\end{array}$ & $\begin{array}{l}\text { Concept solution } \\
\text { Protection } \\
\text { Creativity } \\
\text { Decision making }\end{array}$ & $\begin{array}{l}\text { R\&D } \\
\text { Sensitivity } \\
\text { Experiment } \\
\text { Taguchi } \\
\text { Material choice } \\
\text { Prototyping } \\
\text { Reuse }\end{array}$ & $\begin{array}{l}\text { Value analysis } \\
\text { DFM } \\
\text { DFA } \\
\text { Modularity } \\
\text { Optimization } \\
\text { CAD/CAM CAE } \\
\text { Scheduling } \\
\text { Machinery } \\
\text { Factory layout } \\
\text { Batch sizing }\end{array}$ & $\begin{array}{l}\text { Testing } \\
\text { Marketing } \\
\text { Branding } \\
\text { Distribution } \\
\text { Installation } \\
\text { Sales }\end{array}$ \\
\hline
\end{tabular}

Figure 3: Engineering Design Process by Cather et al.

Of particular note here is that the process immediately jumps to a solution in only the second step, right after an opportunity is identified, and proposes that research happen at a later state after a solution is chosen. Additionally, Cather et al. ${ }^{14}$ make no mention of iteration and view the design process as a strictly linear task.

In Product Design \& Development by Ulrich \& Eppinger ${ }^{15}$, the authors take a ten-step approach to the engineering product design process:

1. Identifying Customer Needs

2. Establishing Target Specifications

3. Concept Generation

4. Concept Selection

5. Concept Testing

6. Setting Final Specifications

7. Project Planning

8. Economic Analysis

9. Benchmarking of Competitive Products

10. Modeling and prototyping

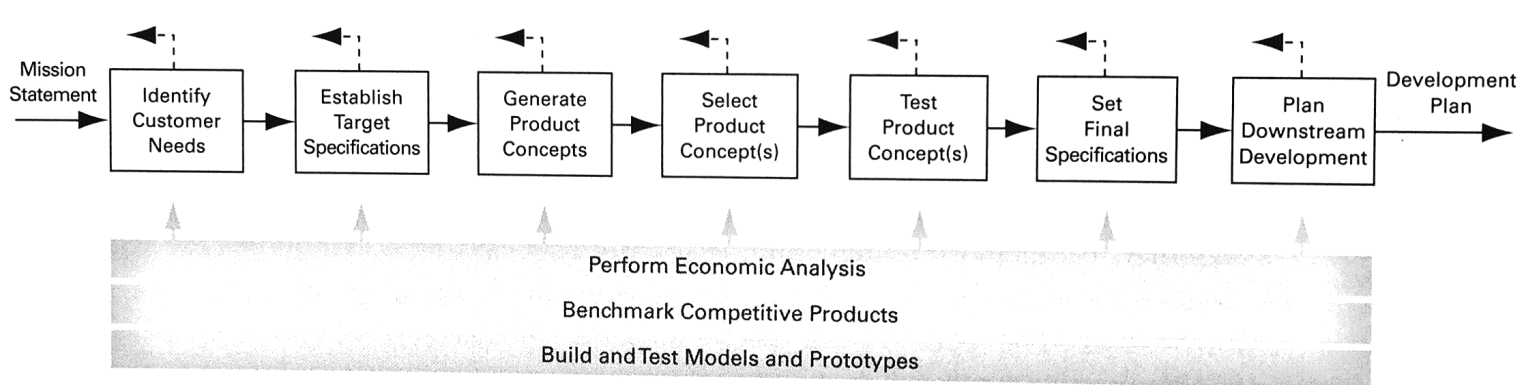

Figure 4: Engineering Design Process by Ulrich \& Eppinger

Ulrich \& Eppinger take an approach to the design process that is heavily influenced by iteration and state, "rarely does the entire process proceed in a purely sequential fashion... in practice the front end activities may be overlapped in time and iteration is often necessary." 15 In their view, this need for iteration 
frequently comes about because the team has discovered new information or gained results of testing a concept, which causes the team to reconsider and repeat previous steps in order to optimize the outcome. It is the authors' opinion that this model by Ulrich \& Eppinger offers the most middle-of-the-road approach on the design process to span the different views from the disciplines of design and engineering.

Regardless of the specific interpretation of the Design Process that one chooses to apply, some version of it is always used in the context of a design project, whether it is being carried out by practicing engineers and designers, or by students in the classroom. Many factors might influence which process is chosen, including workplace culture, the nature of the product being designed, and the experience and expertise of the team members.

\section{Best Practices: Design in the Classroom}

When engineering and design students graduate and leave the classroom, they will likely go out into the world as professional problem solvers in their chosen disciple, where they will be confronted with openended, ambiguous, and downright messy challenges, thus experiential learning will be a key aspect to prepare them for their professional careers. ${ }^{16}$ In the classroom, students in all disciplines under the umbrellas of design and engineering will at some point complete 'design projects' as part of their curriculum. It is the responsibility of the educator to expose students to exploratory projects that mimic real-world design scenarios. The IDEO Field Guide To Human-Centered Design ${ }^{5}$ highlights the need to embrace the uncertainty of real-world projects by stating, "Human-centered design is a unique approach to problem solving, one that can occasionally feel more like madness than method -- but, you rarely get to new and innovative solutions if you always know precisely where you're going." impart this mindset on their respective students by exposing them to open-ended, ambiguous challenges that demand iteration and testing.

Many studies have been conducted over the decades to show that humans are naturally averse to ambiguity. ${ }^{17,18}$ The authors see this reflected in their students' behavior in the classroom when confronted with ambiguous, open-ended, or so-called wicked problems. Wicked problems, according to Rittel and Webber are defined as interconnected, large, and typically social issues such as poverty, homelessness, education, transportation, etc. notably define wicked problems in the realm of social policy as those issues in which, "problems cannot be definitively described [with] ...no objective definition of equity..." and often do not result in clear or definitive answers. ${ }^{19}$

Having each conducted open-ended design projects with their students over the past several years, the authors have each observed the challenges that students encounter when faced with an ambiguous, openended project. Given that the authors teach at two institutions in two different disciplines, it was notable that there were many commonalities in the type of challenges that the students faced, particularly when it came to facing open-ended, ambiguous projects. The mindset of tolerating ambiguity and expecting repeated iteration and failure are important traits in the success of a designer; however this mindset is often only achieved by repeated practice in a suitable environment. ${ }^{2}$ An environment such as the classroom where exercises are relatively low stakes provides a much more suitable setting for practice, as compared to high-stakes exercises of industry.

The following case studies will outline these courses and the common student challenges. It will be helpful for the reader to know some general background about the institutions, departments, and student bodies affiliated with each course:

Abell, whose background is in Mechanical Engineering and Industrial Design, teaches a Fundamentals of Product Design Engineering Laboratory course at Ohio State University in the Department of Mechanical \& Aerospace Engineering. The course student body is primarily made up of senior- and graduate-level students who are studying in Mechanical Engineering or Industrial \& Systems Engineering, however 
students from other various engineering majors also enroll in the course. Enrollment in this course has historically been around 100 students each semester. As many readers will know, Ohio State University is a large, public, institution in Columbus, Ohio. OSU's Department of Mechanical \& Aerospace Engineering is a large department within a large school, and graduates around 250 undergraduate students each academic year.

DeVore, whose background is in Architecture and Design Research, teaches a Design for Social Change in the Department of Interior Design at Columbus College of Art \& Design (CCAD). The course student body is primarily made up of students from majors in Interior Design, Industrial Design, and Graphic Design who are at the junior and senior level. Enrollment in this course is typically around 15 students. CCAD is a small, private, art \& design college in Columbus, Ohio. The total student body of CCAD is around 1,100 students.

\section{Case Studies: Coursework and Curricular Practice}

As professional needs change and adapt, so too must pedagogy change to reflect the current industry landscape. Educators are no longer expected to be the 'sage on the stage' and have the students recite back to them what they have retained, but rather, students in both engineering and design are being pushed beyond a more traditional lecture-memorization format, into project-focused labs or studios which encourage collective creativity and ambiguity. The following case studies describe the curricular practices of two programs - one in engineering and one in design.

\section{Engineering Product Design Class}

This case study comes from a Fundamentals of Product Design Engineering lab, offered by the Department of Mechanical \& Aerospace Engienering at Ohio State University for over 15 years. The course consists of a lecture component (in which students learn theory and background of the design process, design theory, and manufacturing principles) and a laboratory component (in which students engage in a hands-on, user-centered design project). The course emphasizes a human-centered approach to design and is structured to integrate design thinking methodologies with the classic engineering design process. Both the human-centered approach and the integration of design thinking make this course somewhat unique for a mechanical engineering course, as the standard engineering design curriculum does not typically include these aspects. However, it is this unique approach that has contributed to the popularity of the class over the years.

A typical course enrollment for the course in a given semester is roughly 100 students. For the lecture portion of the course, the students all meet simultaneously for a large, twice-weekly lecture, whereas for the laboratory experience the students meet once weekly in lab sections with enrollment no larger than 20. This smaller laboratory setting fosters engagement, teamwork, and collaboration from the students.

Abell has been involved with the course for several years as the instructor of the project-based laboratory portion of the course. The laboratory curriculum is comprised of a semester-long, user-centered design project that the students carry out in teams. The Learning Outcomes for the lab are as follows:

1. Students will have a thorough understanding of the product design process

2. Students will be able to plan and conduct open-ended user research that allows them to gain insight into the needs, goals, and motivations of their user group

3. Students will be able to define a problem, create appropriate problem statements, and write corresponding product specifications

4. Students will be able to propose and evaluate many solutions to a given problem

5. Students will verify and evaluate solutions via prototyping 
6. Students will be able to effectively present information on their project

7. Students will become more innovative problem solvers

8. Students will become more comfortable with solving ambiguous, open-ended problems

The lab project is very open-ended and students have a major role in choosing the direction of their project, which fosters ownership over the outcome. In most offerings of the course, students are paired with a community partner (a local business or organization), to work with on the project for the semester. (In some offerings, the connection to the partner is prearranged by the instructor, but in other offerings the student teams find their own partner groups. Regardless of the arrangement, the project proceeds in the same manner.) This is a mutually beneficial arrangement for the students and the community partner. The students are able to get first-hand experience working with a "client," and the community partner receives proposals for feasible solutions to solve an actual problem within their organization. The community partners are coached to avoid asking for a pre-determined solution to a known problem; rather, they are encouraged to work with the students to define the problems that might be tackled for the project, for which the students will later generate solutions.

Because the community partners have changed over the terms, the nature of the project topics has varied widely. Given that the project is so open ended and the students work with the users to determine a project direction, the results of the project have also varied widely over the years. Community partners have encompassed a range of groups including: the OSU Police Division, Columbus Compost (a local composting service that provides weekly curbside pickup), OSU Sustainability Services, Land Grant Brewing (a local craft brewery), medical professionals at local hospitals, private pilots, landscapers, grave diggers, fuel transport truck drivers, home brewers, and many, many more.

To begin the project, the teams spend several weeks of the semester conducting user-centered research and background research so that they can have first-hand experience with the problems their users face as well as the context and environment in which the users are working, and also be fully informed on the state of the art related to their project topic. Following the research, the teams work to create problem statements that define the problem in a way that is mindful of the users' context and constraints. Next, the teams go through several iterations of idea generation before choosing concepts to move to prototyping. The teams conduct three rounds of prototyping, starting with very low-fidelity, low-investment "sketch" prototypes and culminating with functional proof-of-concept prototypes. (Given that the class is only one semester, this is as far as the students are able to take the prototyping.)

In the beginning of the term the project stakeholders (students, community partners, and instructor) do not necessarily know where the project will lead, or what type of product will be designed as a final result. The project is intentionally left very open ended so that the students can hone their problem definition skills in addition to their problem solving skills. This is reflective of one of the core tenets of design thinking, where one should work on understanding the problem before converging to a solution.

The engineering design project is broken down into the following phases:

\section{Research}

Students embark on two kinds of research: background research and shadowing research, documenting each thoroughly in a team website. For the shadowing research, students are required to go out into the field on site visits to see their users in action, and to gain empathy for the users and the problems they may be experiencing. User shadowing is typically not included in design projects that follow a classic engineering design process. The goal of this activity is for the students to empathize with the user's needs, problems, and motivations so that the students can eventually narrow in on a design that is contextually appropriate for the user. These research 
activities force the students to jump headfirst into the design process and learn as much as they can about the problem space right off the bat.

Though this research assignment is arguably the most important step of the design process, the students often find it to be the most overwhelming. With complex, open-ended problem topics it's necessary to conduct a wide range of research to understand the system-level view of the problem space. Though casting a wide net is important in order to see the big picture, the act of doing so tends to make the students feel like they are straying further from a solution, because all of their analytic instincts are telling them to just converge on a solution as soon as they see a problem! Providing time and discussion for reflection after the students conduct research has proven helpful in allowing the students to acclimate to a complex, open-ended project.

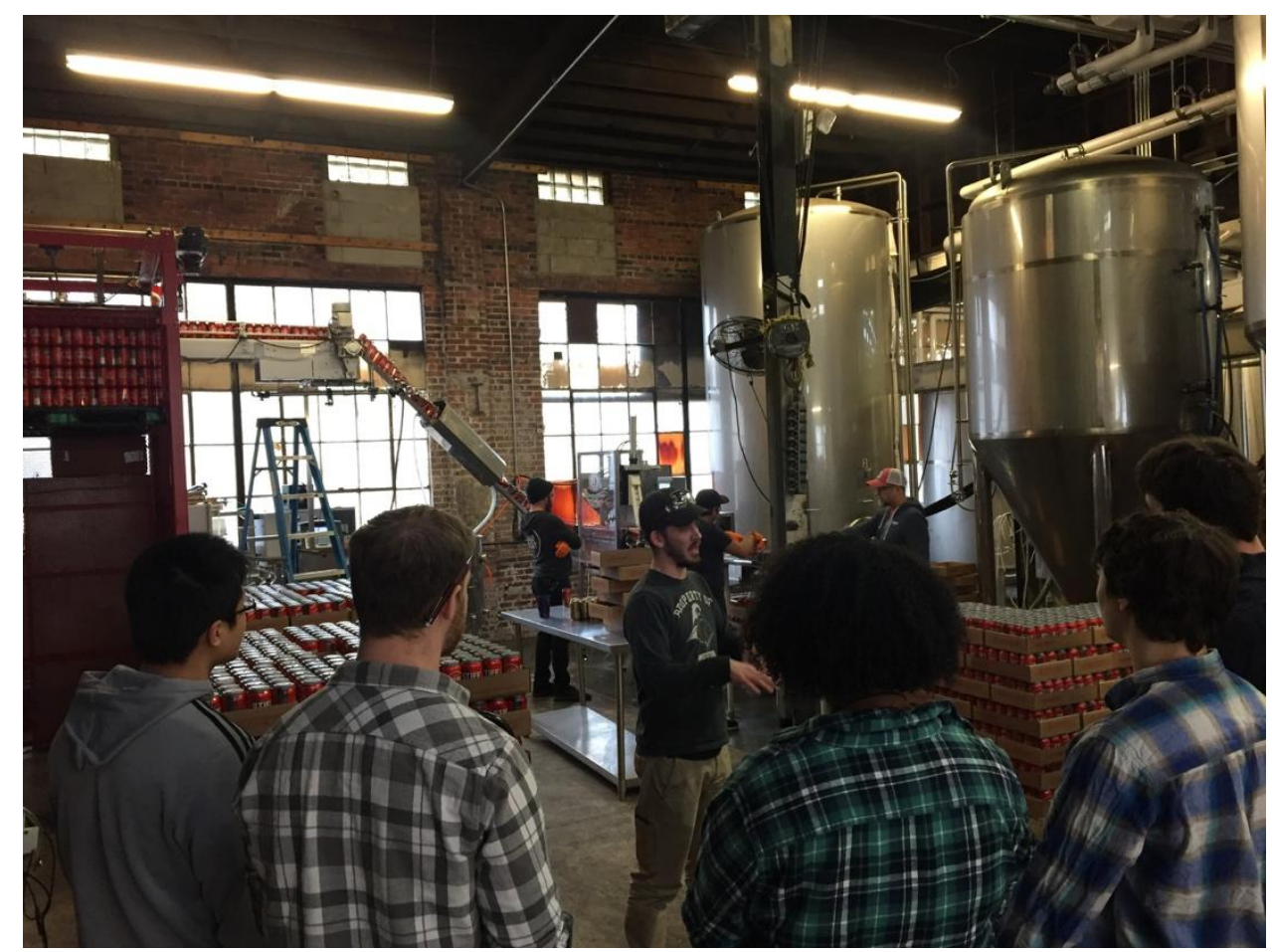

Figure 5: Students visit Land Grant Brewing to see first hand the tasks and challenges that a brewer faces on the job. 


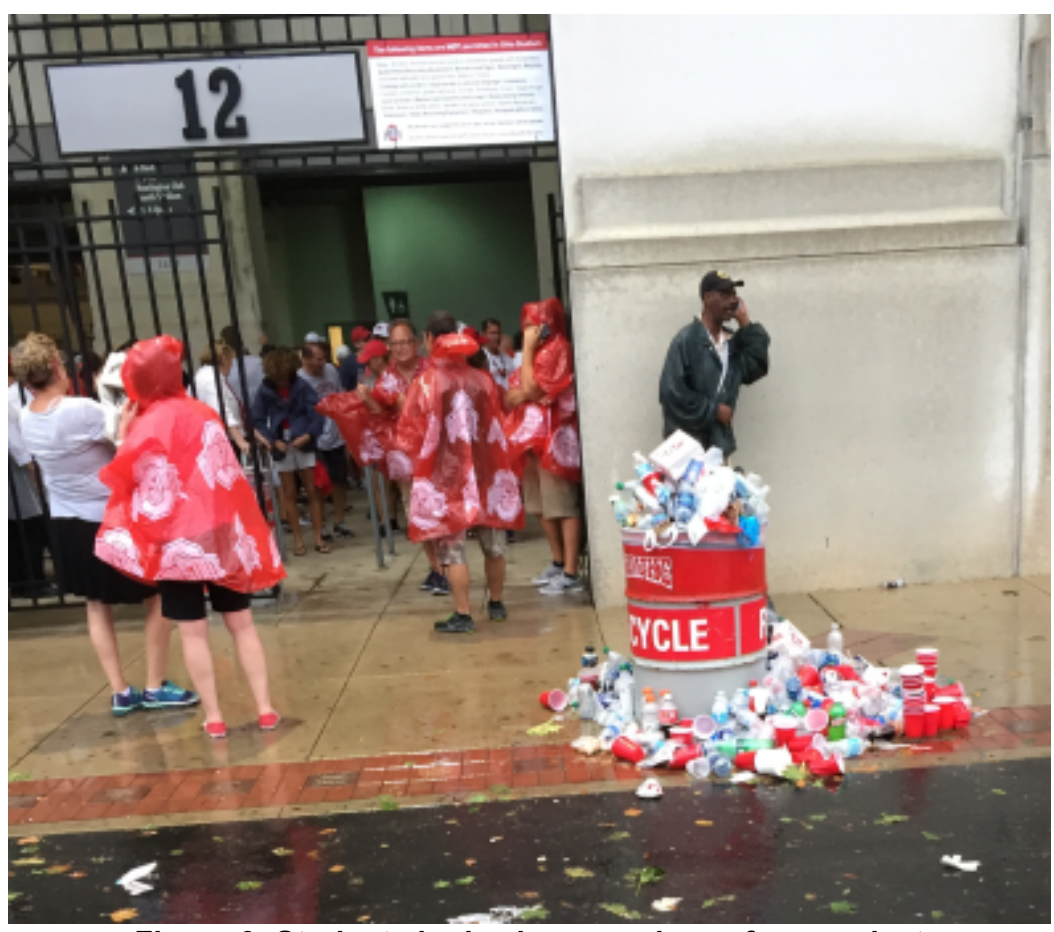

Figure 6: Student shadowing experience for a project to improve recycling at OSU football tailgating

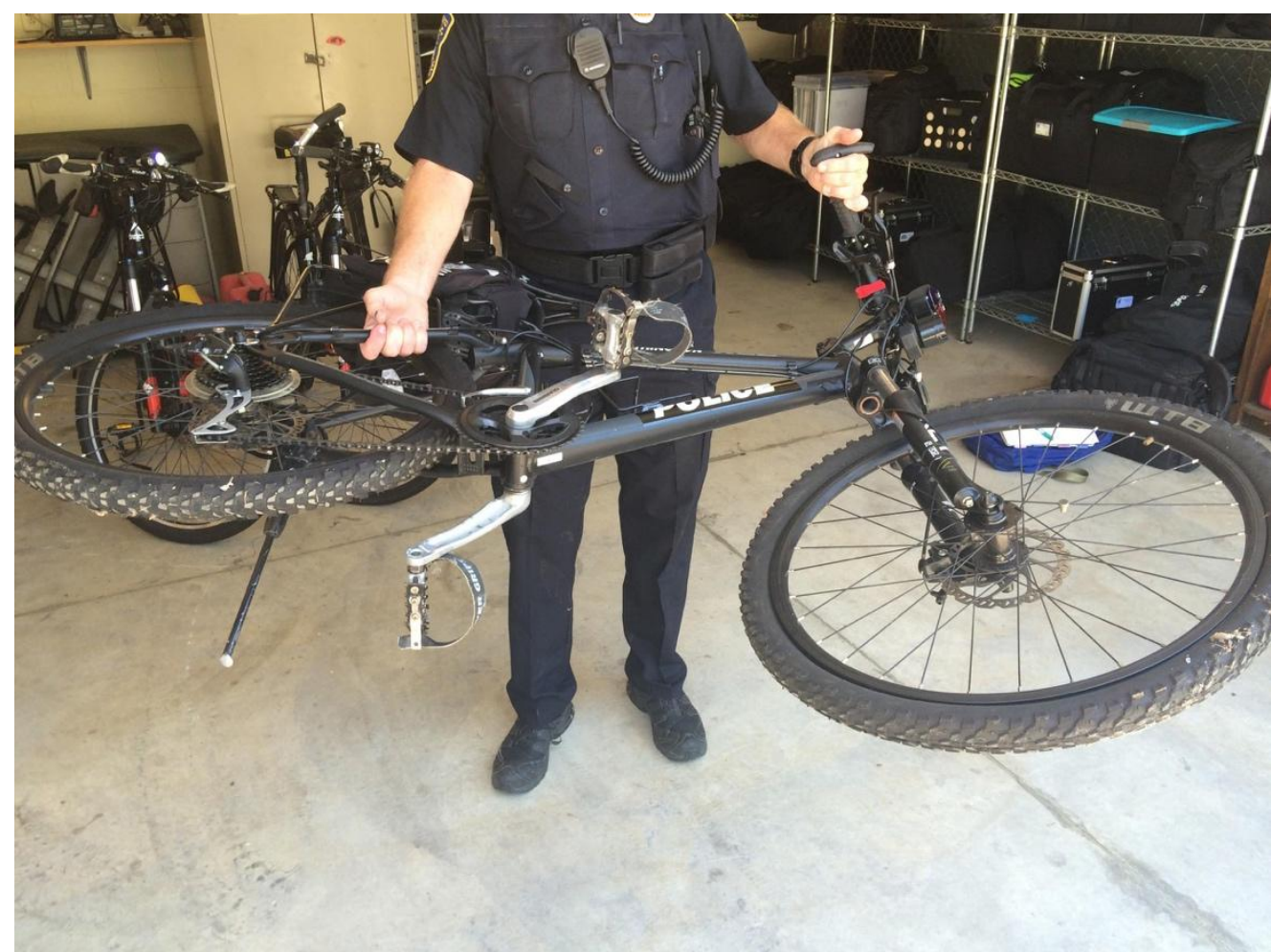

Figure 7: During student shadowing, a local police officer demonstrates how he would hold a bike for crowd control. 


\section{Problem Definition \& Product Specifications}

Based on shadowing observations and research, teams conduct root cause analysis of observed user problems and create problem statements that will give the team design direction to create solutions. Ideally each team has three to five problem areas to pursue at this point, and they write a problem statement for each problem area. The problem statements are crafted in a way that they state the goals of the solution, but not what the solution actually is. Corresponding metrics are developed for each problem statement. Combined, the problem statements and metrics constitute a set of Product Specifications, which will aid the teams in generating appropriate solutions and then later in evaluating the prototypes.

This phase of the project gives teams time to pause and think about all of the information they learned through research, and empathize with the user's experience in order to capture their needs and goals in appropriate problem statements. Writing problem statements also helps the teams narrow in on a few well-defined, actionable goals that will solve some portion of the big, messy problem at hand. This often helps the students feel more hopeful that, yes, they will one day reach a solution to solve some aspect of the big, messy problem.

\section{Concept Generation}

Each team conducts several iterations of concept generation to address the previously developed problem statements. First each student chooses a problem statement for which they individually generate ten concepts. Then the team comes together for brainstorming and to share their initial work. The team goes through another round of idea generation to build on their initial concepts. This concept generation is documented by the students in the form of hand drawings. This reinforces that ideas are best communicated visually, and aims to break down the widely-held notion amongst engineers that one must be 'artistic' in order to draw. Here, emphasis is placed on drawing for visual communication. At the end of the activity students select the best concepts for each problem statement.

This phase of the project benefits from a diversity of viewpoints from the team members. With diverse backgrounds and experiences, the team members will approach solution generation with a different lens. This leads to a greater diversity and quantity of ideas, which has a positive impact on the overall quality of ideas. Promoting team discussion to build on the ideas of others helps the students reflect on their work and identify the solutions that would work best in the user's context. 


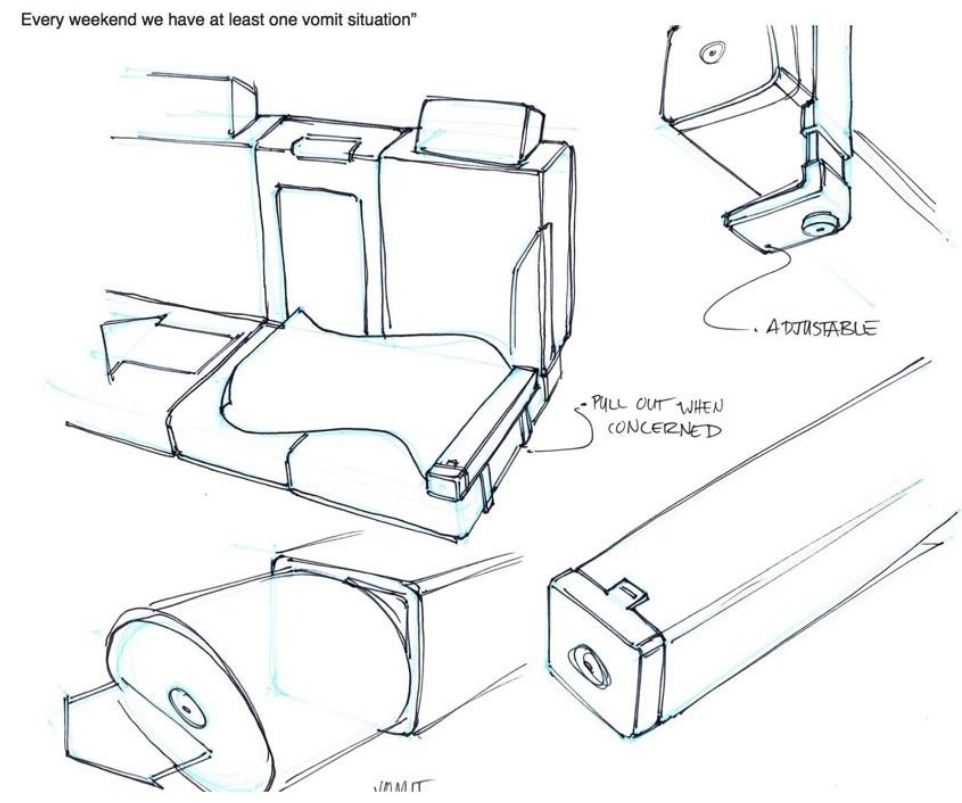

Figure 8: Student sketches exploring a problem in the campus community: Student Safety Services offers late-night rides to students, and needs a way to protect their vehicles from so-called "vomit situations."

\section{Prototyping \& Evaluation}

The students embark on three rounds of prototyping (sketch prototypes, functional prototypes, and refined prototypes) before performing an evaluation of their solution. The first round of prototyping is intentionally a very low-investment activity. The goal is for each student to produce a quick, so-called 'sketch prototype' that brings the concept off of the 2D page and into 3D space. Things are kept low fidelity so students do not invest too much time, money, or emotion in this first iteration, as some ideas will be abandoned. Cardboard and duct tape abound at this stage. 

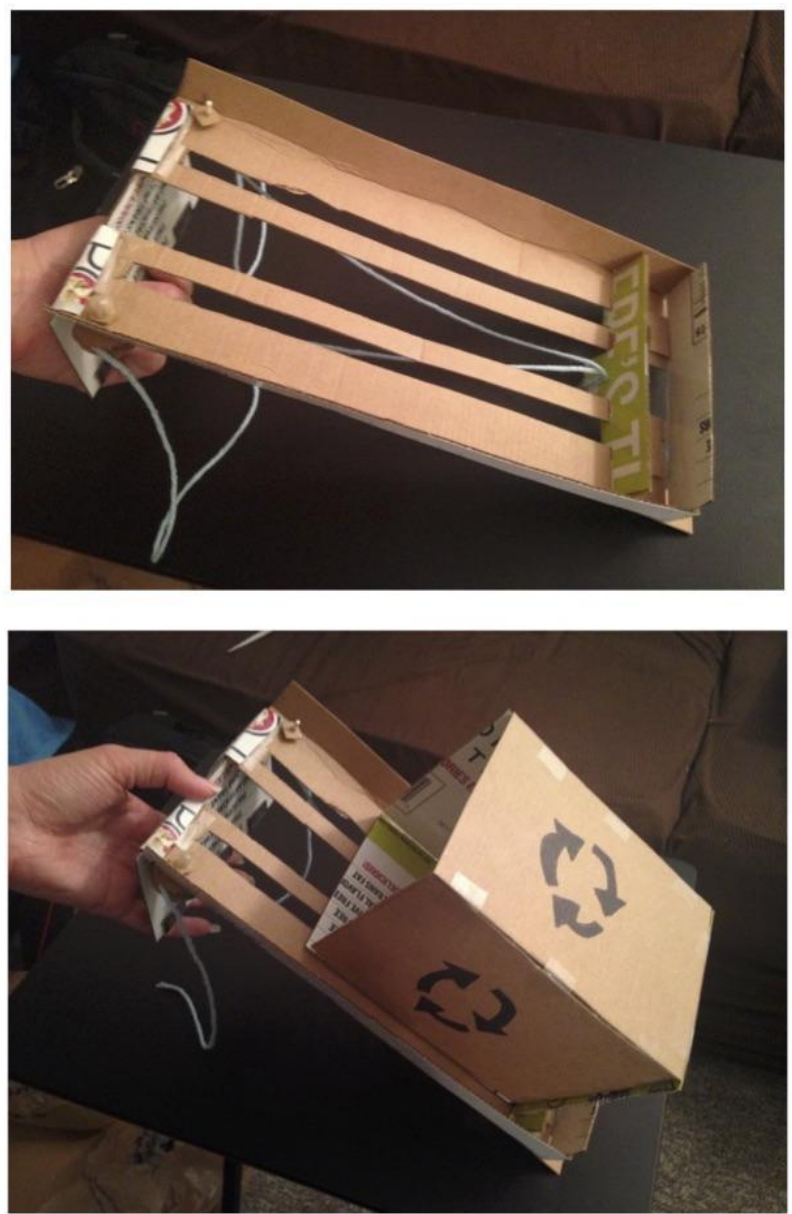

Figure 9: Initial, scaled-down prototype of a student concept that would help a person safely empty a 50 -gallon recycling bin into a large dumpster.

Next the team chooses a 'winning' concept to bring to the next round functional prototyping. The goal in this activity is to have the team verify that their concept can achieve the stated goals from the problem statement. This prototype should function and convey use, though the construction may still look very rough. Some might consider this a "works-like" prototype. 


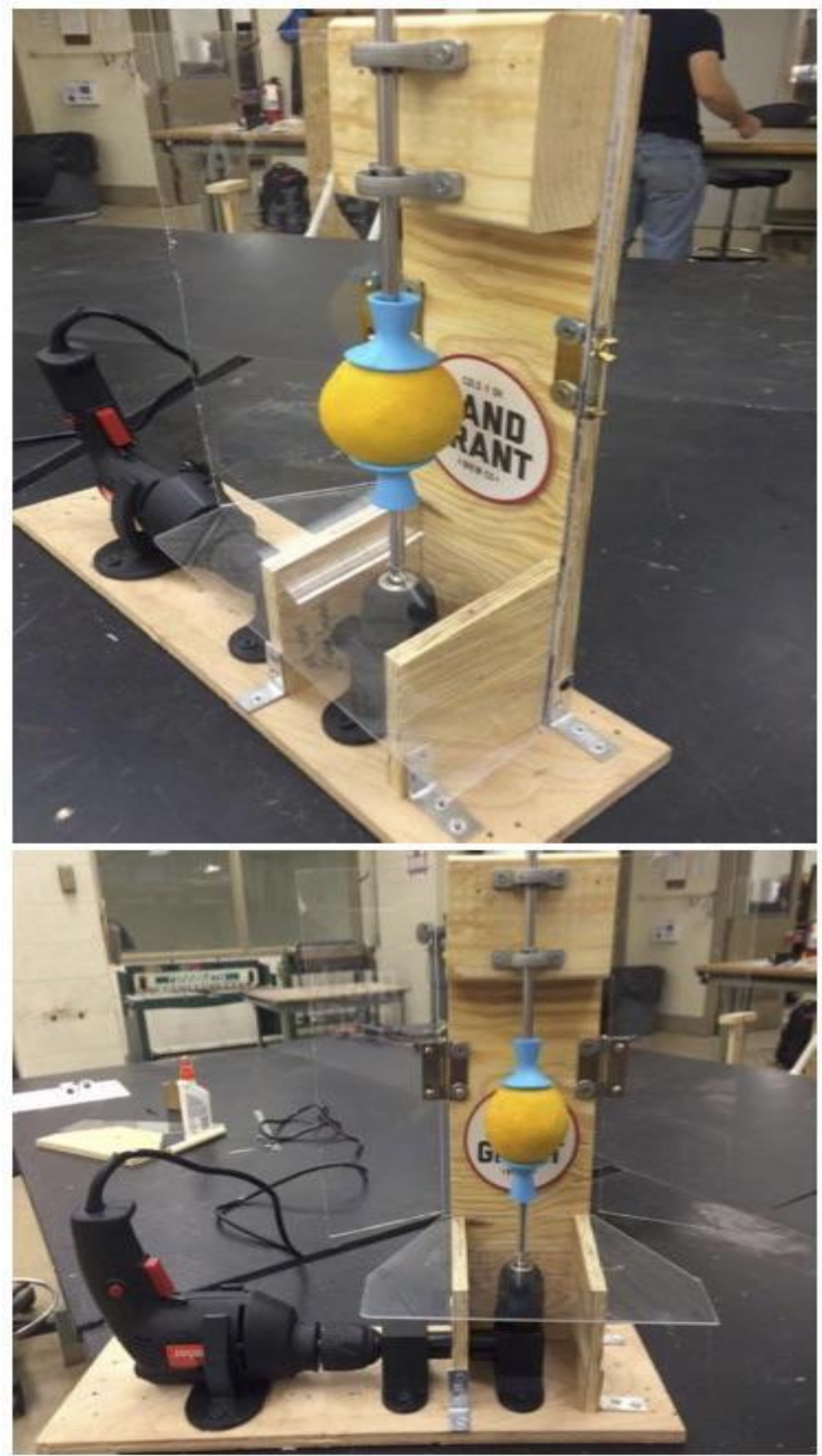

Figure 10: Functional prototype of an automated orange zester. The team worked with the local craft beer brewers at Land Grant Brewing, who needed a solution to help them efficiently zest 1,200 oranges for a seasonal beer, while keeping the whole orange intact so the fruit would not be wasted.

Finally, students build a refined 'proof-of-concept' prototype. This prototype should indeed be functional but it also incorporates improvements and refinements from the previous iteration. The goal is to have a fully-functional prototype that conveys all aspects of use. However, due to the 
constrained, 14-week semester timeline, and due to the fact that there is no class budget, the prototypes are by no means expected to be an actual "product" or permanent solution that is to be given to the users.
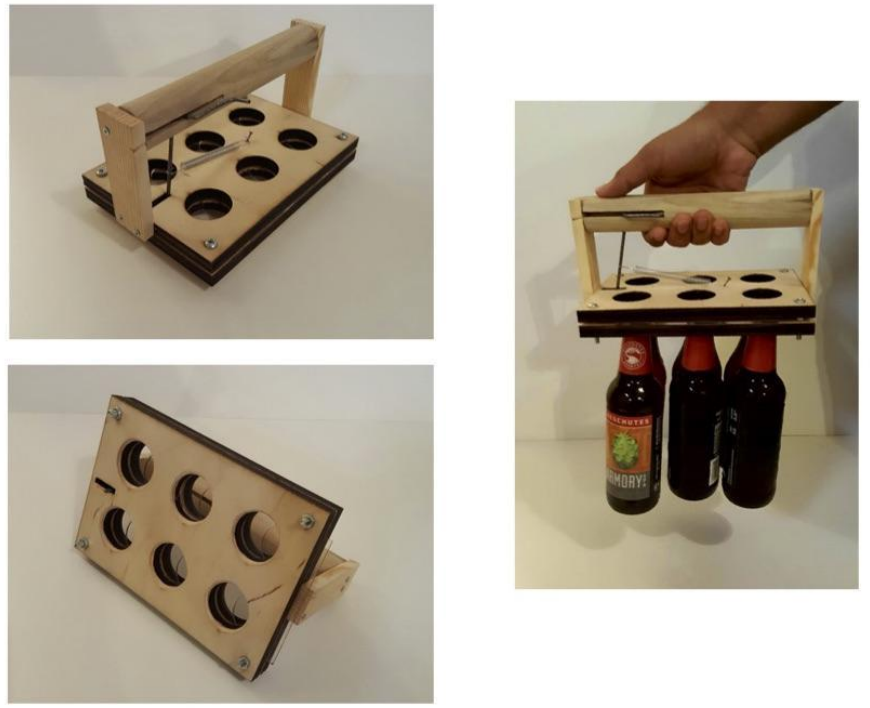

Figure 11: A device designed by a student team to help workers in a craft brewery ergonomically and efficiently move six bottles from the assembly line to the six-pack holder.

Teams must conduct a self-directed evaluation of their final prototype based on the metrics they created previously in the project. The type of evaluation may vary widely depending on the nature of the given project, as well as the skillset and background of the students on the team. The evaluation may be theoretical (e.g., calculating the minimum input force needed to operate a device) or it may involve a simulation (e.g., conducting a finite element analysis).

Prototyping \& evaluation are activities present in nearly all engineering design processes, so this phase of the project is where students start feeling much more comfortable: they have several defined solutions, and now they are setting about to develop those solutions.

\section{Final Event}

Teams make a poster to summarize and convey their design process for the project, and to reflect on their experiences. The posters are displayed at an end-of-semester showcase that is open to the community. The community partners as well as other members of the university community come to this event to see the results of the student project. 


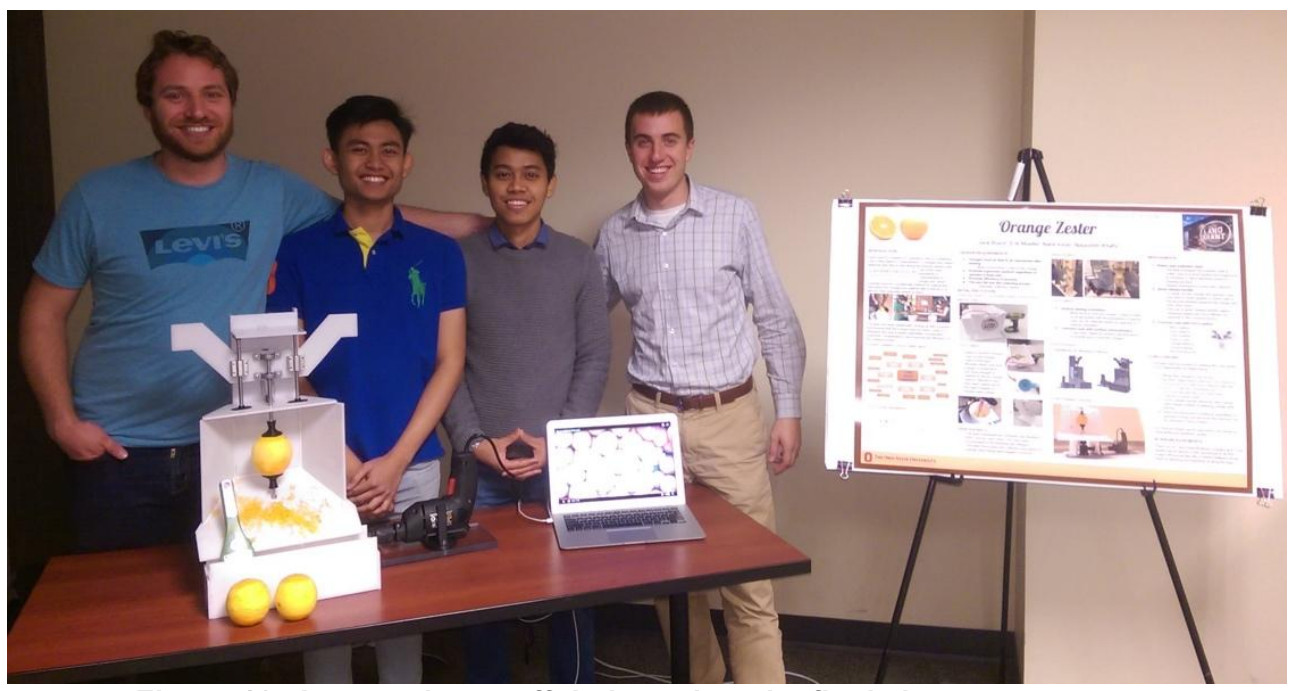

Figure 12: A team shows off their work at the final showcase for the engineering product design project

Much of this project is rooted in the classic engineering design process of 'design, build, test.' However the project is layered with elements of design thinking and human-centered research, which add a unique aspect to the project, particularly in the setting of the engineering classroom. In the beginning of the term the project stakeholders (students, community partners, and even instructor) do not necessarily know where the project will lead, or what type of product will be designed as a final result. The project is intentionally left very open ended so that the students can hone their problem definition skills, in addition to their problem solving skills.

\section{Design for Social Change Design Course}

The design case study course, Design for Social Change, is an interdisciplinary elective course taught and developed by DeVore at Columbus College of Art \& Design. Typically, the college teaches design in the more formal approach in its delivery - the student learns a technical design skill in a field of industrial, interior, fashion, graphic design, film, photography, etc. and move into that field as practitioners and creative leaders.

The course within the college is an elective and small in comparison to the engineering course described above. The first year, the course ran with 10 students enrolled from Interior Design, Industrial Design, and Graphic Design programs. The second year, there were 15 students enrolled from similar interdisciplinary majors.

The course consists of several lecture and discussion sessions to review readings, documentaries, lectures, and current practice regarding work of designers doing socially-engaged work. The purpose of the course is to encourage thoughts and projects that involve social good and bring students out of their design bubble and into a more empathy-centered approach to designing projects, experiences, and products that benefit society as a whole. Often, these projects seem 'wicked' as one issue or problem tends to uncover other issues. The entire course rests on the ability of the students to reflect and adjust their opinions, thoughts, and perspectives based on experiencing other thoughts, collaborating, and seeing the world through different lens than they normally do in a typical, client-directed design project. The nature of the projects and assignments in this course all surround ideas of human empathy, understanding other cultures, understanding other socioeconomic backgrounds, and ways in which designers have an ability to amplify or mitigate change to help others. 
To tackle the issues around 'wicked problems', the course is divided into the following parts:

\section{Research \& Problem Exploration}

For the first part of the class, the lectures and discussions focus on understanding and exploring how existing designers and social activists are trying to help communities in a variety of different ways. The class discussed the power of design; designers can sometimes add to the negative effects of society if they are not careful of their actions and are not empathetic with the end-users, constituents, or cultural implications of their designs. The class discussed why (and why not) a variety of projects based on design-thinking were successful.

Examples of topics that were discussed were issues surrounding poverty, racial equality, voting rights, and a variety of interconnected issues. A guest lecture by a government social services worker helped to paint a picture for the students of how difficult these problems were to solve: the guest described an instance where the city was sending out a pamphlet of resources to help individuals who were having trouble making child support, called, 'frequent offenders'. However, in the most extreme cases of individuals failing to pay child support, they quite often did not have a permanent residence, and thus, could not open a bank account. So, the 'frequent offender' could potentially have the money to give for child support, but no feasible mechanism to deliver it. The guest described that the city had funds available to help with these instances, but it was difficult to reach the 'offender' due to a lack of home address. These problems could then snowball for the individual, putting them at risk of not seeing their children, and perhaps even going back to jail. This is a prime example of a wicked problem: one issue that can magnify and have a cascading effect on several other issues.

In the context of the class, Wicked Problems were defined as interconnected, large, and typically social issues such as poverty, homelessness, education, transportation, etc. according to Rittel and Webber notably define wicked problems in the realm of social policy as those issues in which, "problems cannot be definitively described [with] ...no objective definition of equity; policies that respond to social problems cannot be meaningfully correct or false; and it makes no sense to talk about 'optimal solutions' to these problems... Even worse, there are no solutions in the sense of definitive answers." 1 It is this feeling of the sheer enormity of the wildness of these topics and the unknowing answers that the students often struggled with.

Individual students were asked to gather this wild research and embark on a topic of their choice to research for a paper and presentation assignment. One such student embarked on an exploration of voting rights and the complex nature of voting - aptly timed during an election year. Another student explored issues surrounding healthcare and healthy living - touching on the interconnected nature of the medical health system all the way to lack of proper bike lanes in the city. The following diagram is an example: 


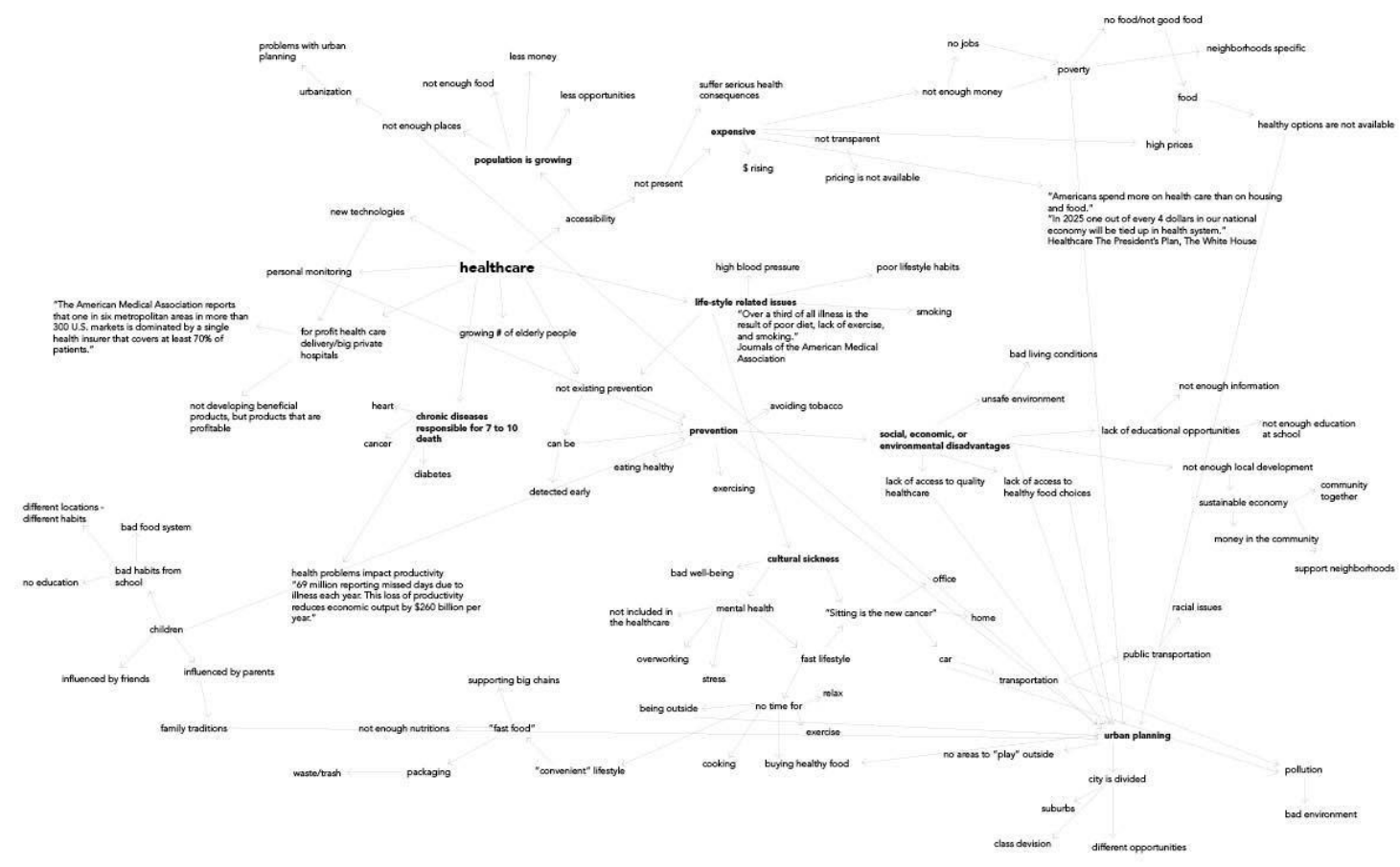

Figure 13: Students were asked to create mind maps of their 'wicked problem' topics - this is on healthcare 


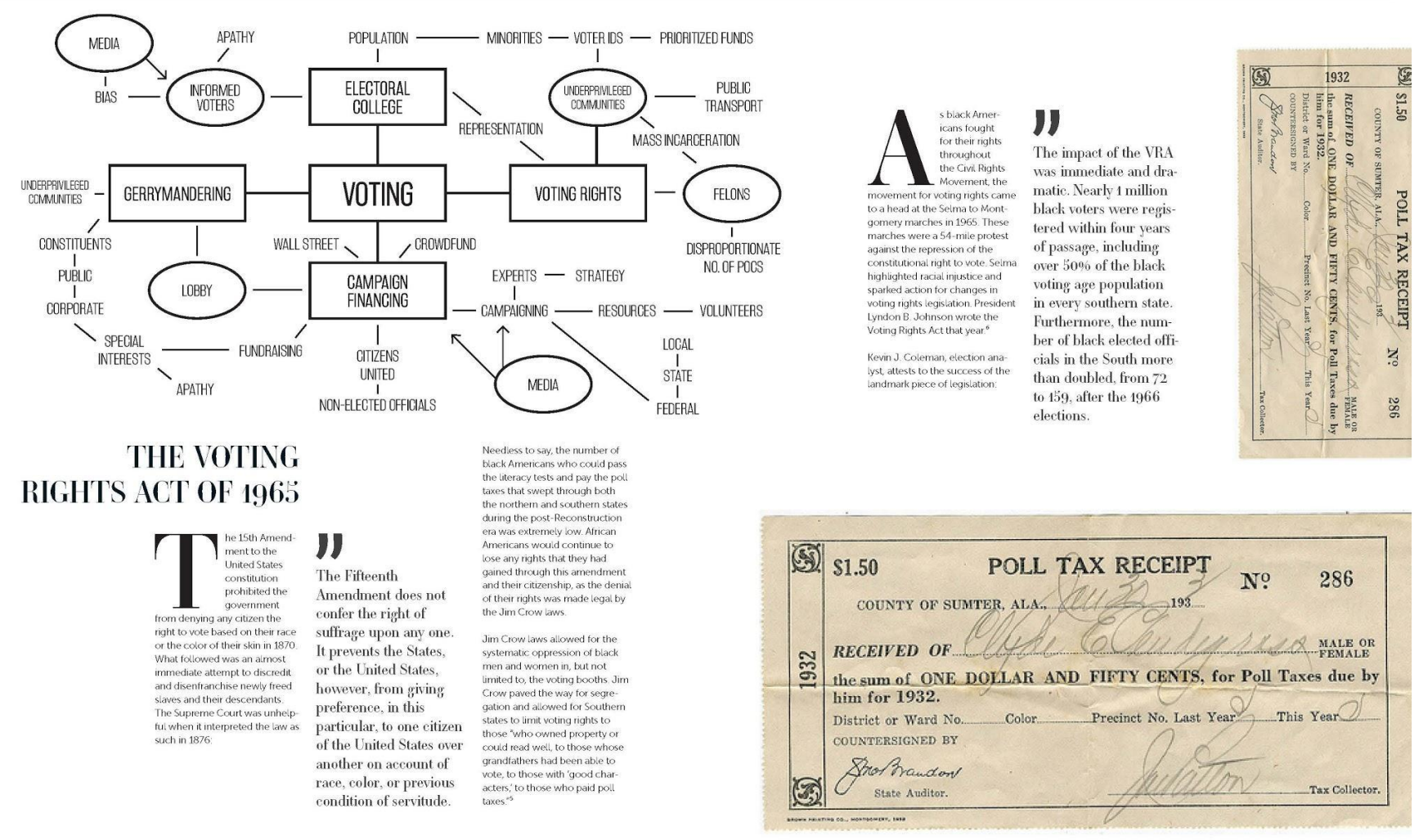

Figure 14: Wicked problem mind map of voting rights

Students process these wicked problems verbally and visually so that they may unpack the complex nature of the problems with the class. Mendel and Yaeger state that "Visualizations aid in sense-making and cognitive processing of complex information. It accomplishes this through framing ambiguous states, bringing order to complexity, making sense out of seemingly unrelated things, and finding insights that are buried in data." 20

\section{Shared Experiences in Empathy}

The students, as a class, also participated in volunteer activities together at a local free clothing store. As a group, the students divided up and spent the day helping individuals pick out clothing, helped volunteers sort donations, and helped check out free items at the local donation center. The students reflected on these experiences as a class, and also in their individual blog assignments. From that volunteer experience, one student noted, "I loved the volunteer trip. I don't really take the time to volunteer too often because I tell myself I don't have the time for it. But I should make the time for it."

Further on into the semester, the class participated in a 'poverty simulation' in which the students were prompted through an exercise by an outside party that assisted in assigning roles for each person, allowing them to walk in the steps that someone might have to go through if they were in a variety of low-income scenarios. 


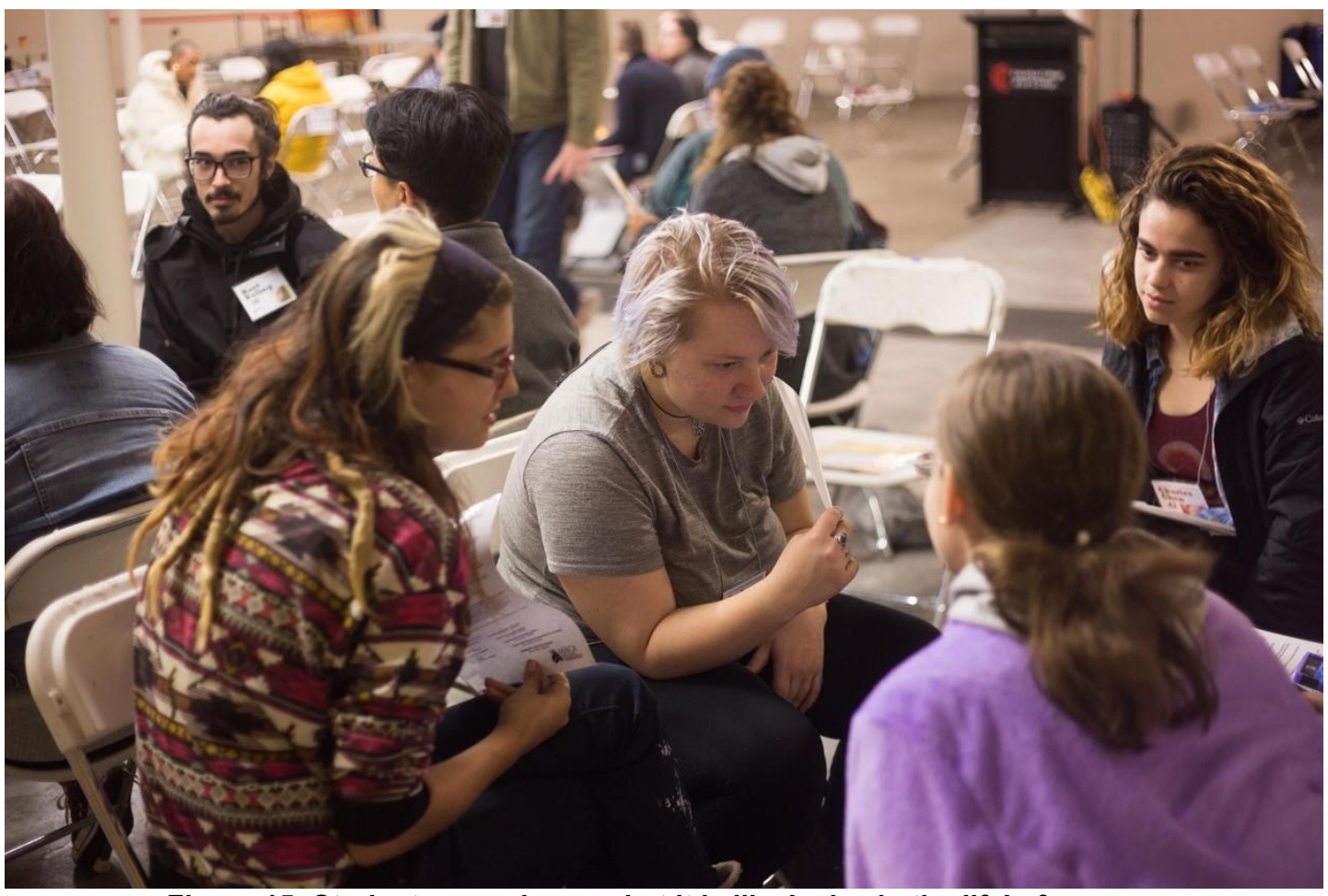

Figure 15: Students experience what it is like 'a day in the life' of someone below the poverty line by having mock "families" that they need to take care, pick up food stamps, pay rent, and ride the bus to their jobs.

\section{Reflections}

Throughout the course, and especially in the first eight-week section, the students reflect upon their experiences in a class blog:

"I have never even heard about this term, wicked problems. So, the main topic of our class are wicked problem. Everyone has to pick one and first write a paper about it. I started to be super excited and also very overwhelmed, already. I will try to work as hard as I can in every class, and now I can see that handling wicked problems can be quite a task. I am excited and I am trying to figure out what to do next." - Industrial design student

"There were several instances throughout the class where I was able to reflect on the choices I have made in bettering the community in which we live. Because of these reflections, I started to see a lot of this class brought into my senior thesis."

Not only was this reflection process a consistent dissemination for the student, but the experience becomes a part of the class discussion. Students connect reading material to team projects and activities, and participate in critiques with other students.

\section{Collaborative Projects}

Lastly, the class is divided into teams to tackle a variety of wicked problem issues, inspired by the research papers produced in the first part of the semester. Students paired up based on alignment in topic interests. For the project, students explore topics and propose 'mitigations' that could help alleviate some of the stress or hurdles that individuals, cultures, and communities have to go through during these crises or problems. These mitigations discussed in class were not intended to be full 'solutions' but instead, rather, ideas on ways in which designers could provide insights or 
assistance. This experience was difficult for some designers to grasp, in that often in their design courses they are asked to provide solutions and resolutions, rather than stepping back and looking at these bigger, interconnected issues.

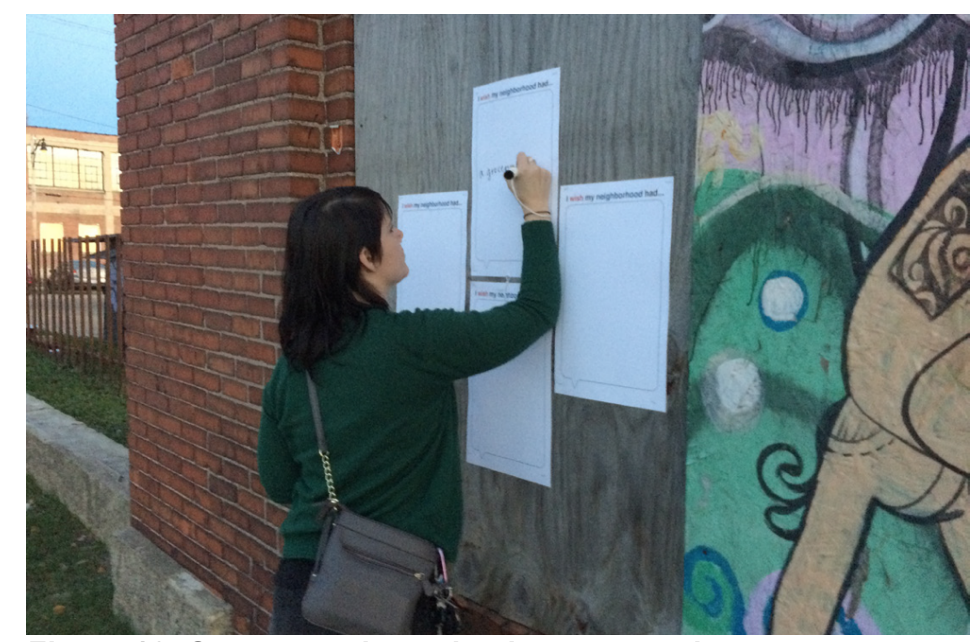

Figure 16: One group, investigating community access

and transportation, posted prompts in 7 different neighborhoods that posed, "I wish my neighborhood had..."

One example project involved a team that explored the 'wicked' nature of neighborhood access and transportation in the city, while another team investigated issues surrounding veteran's affairs. Teams embarked on several primary research explorations to understand their 'wicked problems': the neighborhood group chose to create posters that they posted in several neighborhoods in Columbus that read, "I wish my neighborhood had...." and hoped that community members would fill the posters in. A variety of the responses included people writing things like, "More access to fresh food" or "More streetlamps," but also the group noted that one child had written, "A friendship place." which the team enjoyed. The veterans affairs group interviewed several veterans, were veterans themselves, and took a trip to the VA hospital in town. 

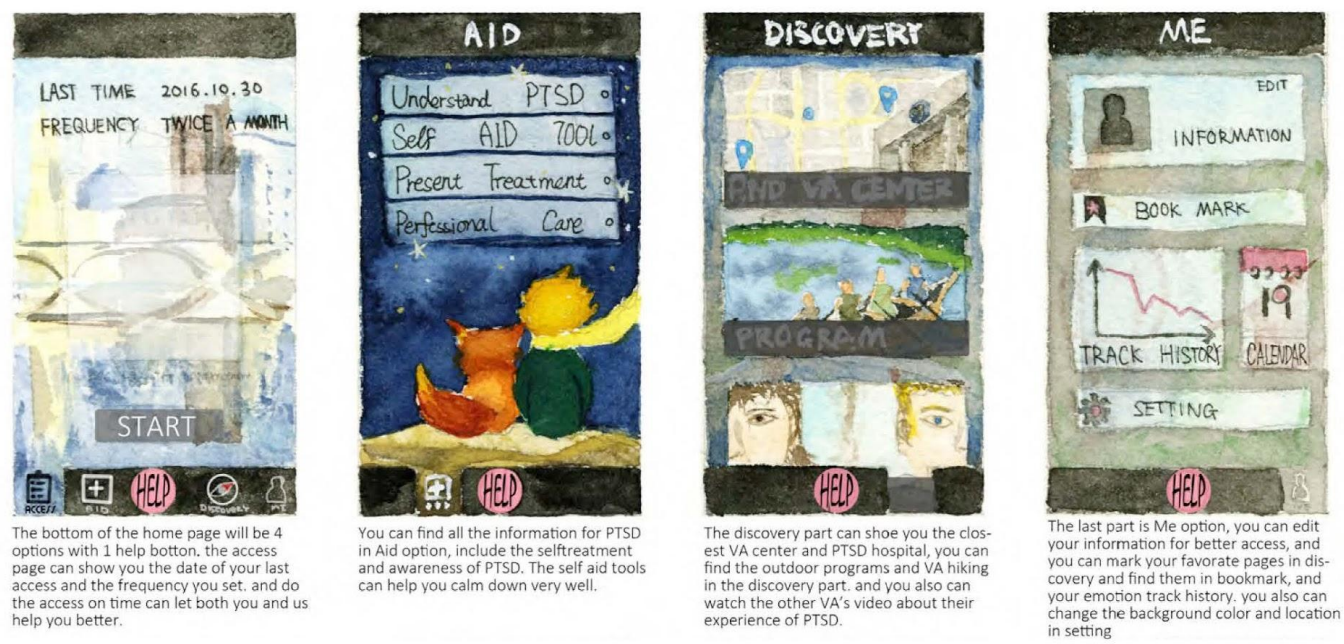

Figure 17: Students proposed ideas and services that could potentially help veterans - not defining how this would occur but providing big-picture ideas as mitigations for this complex problem.

\section{Final Event}

Teams created a poster and/or visual representation of their projects to describe and present. Their work was displayed over the lunch hour at the college so that other students and staff from other disciplines and outside the course could come learn from the teams in a 'science-fair' style presentation.

Throughout the course, the students seemed resistant to the idea that the class would investigate topics without proposing one set design solution. Instead, the goal was to explore how big topics can become, acknowledge this, and learn to explore issues from a big-picture, human-centered perspective.

\section{Embracing Ambiguity: Lessons Learned}

The extremely open-ended nature of the projects described in the above case studies are often unfamiliar territory for engineering and design students; it is unusual that students are presented with a project where they don't know what the outcome will be, or how the solution will be manifested. In design fields, students are typically given a project 'client' or goal and often quickly iterate several solutions to narrow down the scope. Many engineering students report that when presented with a project such as this, they feel conditioned to quickly jump into generating solutions to solve the problem most efficiently, as this is how they've been 'trained' in the rest of their engineering coursework. As Kelley \& Kelley state in Creative Confidence, "When confronted with a question or a challenge... people with strong analytical skills tend to snap instantly into problem-solving mode. They leap for the finish line and then start defending their answers."1 
This is exactly the type of student behavior that is witnessed by the authors. Even the students identify this behavior in themselves, which is evidenced in reflections that the students from Abell's Product Design Engineering class at Ohio State University. The following quotes come from reflections after the first two assignments in the product design project, at which point the goal was to identify problem areas, then write problem statements and metrics-- but not yet identify any solutions:

$$
\begin{aligned}
& \text { "...the team found it difficult to not create a solution [during this assignment]" } \\
& \text { "Ensuring our team did not design any type of solutions was also a challenge." }
\end{aligned}
$$

"One of the challenges for the group to complete this task was not writing the [problem] statements in a way that they implied what the solution might be"

"The most challenging part of this assignment was creating good [problem] statements... We were tempted to get too specific and push the statement toward a specific solution."

Students in DeVore's Design for Social Change course at Columbus College of Art \& Design were asked to regularly reflect on how the process was going within their team projects, and many students had trouble with the open-ended quality of design thinking methods. The students needed to 'resolve' their projects by simply coming up with concepts and ideas for ways in which their wicked problems could be mitigated. Because the work the students were doing did not involve coming up with a product, a space, a specific tangible outcome, the work done in this time was often perceived as time wasted. However, several students also reported that after the iterative team-based collaboration projects were complete, it was easier to see the bigger-picture goals of mitigation and discovery-- rather than the specific outcome.

The activities surrounding ambiguity are often met with resistance by students who typically seek to see things in black and white, and have a strong desire to find "the right answer" to a problem they are solving. In many instances, as we can see from the case study examples and others alike, students need to be exposed to ambiguity if they are to succeed in a rapidly changing world, with often no real visible conclusions present and often filled with wicked problems.

\section{Framework}

As instructors of open-ended experiences, the authors have found similar methods and tools to be effective in acclimating students to this process of ambiguity. The authors have several commonalities and lessons learned surrounding how to manage and work with students to deal with ambiguity and have developed key themes found in each of their courses. Each item within the framework can existing throughout a course -- and should be scaffolded throughout the project.

The following key threads outline these commonalities and how they have been implemented in the classroom experience. They can and should exist throughout the projects that occur, as well as throughout the semester to have the most impactful experience. Abel and DeVore have collectively found that getting students to collaborate, reflect, mitigate, acknowledge, overwhelm, and empathize throughout their projects has had the most benefit to provide a mechanism in which students are more comfortable and confident with projects. 


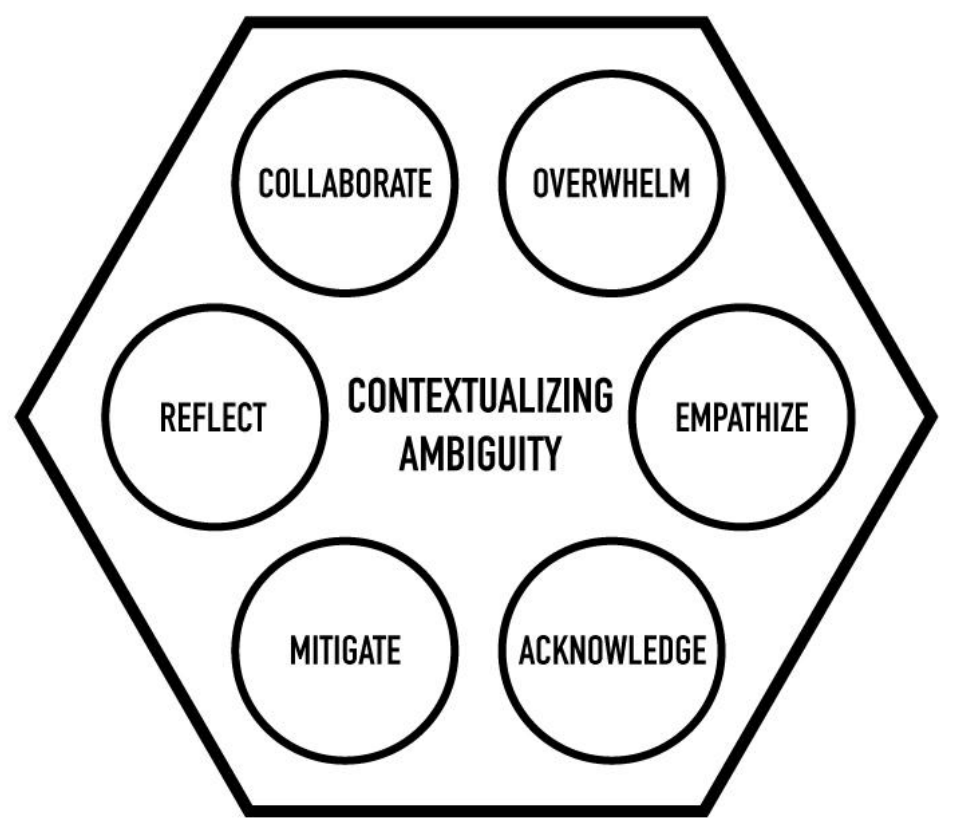

Figure 18: The proposed framework for contextualizing ambiguity

- COLLABORATE

What can the instructor can do?

Get students to work in teams early and often

Encourage students to work through minor and major problems together

Promote cross- and interdisciplinary teams whenever possible

\section{Why is this helpful?}

By encouraging students to collaborate earlier in the semester/project and get comfortable with the sharing of ideas that inevitably comes with collaboration, a mechanism is provided for students to feel more comfortable with the project and to not get 'stuck' on their initial ideas.

- OVERWHELM

What can the instructor can do?

Encourage large, 'wicked problem' projects

Use open-ended, real-world scenarios

Help students to understand the big picture

Map out interconnected parts of the problem

\section{Why is this helpful?}

Though it may not be intuitive, overwhelming students with the complexity of the problem is important and helpful because it simulates 'real-world' problems. It allows students to see the complex, interconnected issues at hand, and the classroom provides an appropriate, low-stakes environment for them to try their hand at managing these messy, interconnected problems. The students can practice sifting through the big picture goals and learn how to work through problems that are incredibly complex. 
- MITIGATE

What can the instructor can do?

Break down the problem to find smaller goals

Identify individual action items

Solve what you can in the course time frame (true 'wicked problems' cannot be solved in one term, or even one academic year)

\section{Why is this helpful?}

Helping students to understand how to break bigger ideas down will allow them to identify smaller goals within a larger project. Also, it allows students to see how mitigating a problem can have important impacts without fully solving it.

\section{- ACKNOWLEDGE}

What can the instructor can do?

Talk with the students to acknowledge that the problem at hand may be overwhelming

Encourage the students to 'trust in the process': even if they don't see a clear solution now, encourage them to trust that one will evolve as they get a better grasp of the situation.

\section{Why is this helpful?}

In both case studies, the authors noted difficulties with students wanting to finalize a problem too early, or that students might get stuck on an idea and not let it go. To move beyond this tendency, it is important for the instructor to reiterate how vital it is that sometimes the answer is yet unknown. Acknowledging to the student that this is uncomfortable helps create trust between the student and instructor, and thus trust in the process.

\section{- EMPATHIZE}

\section{What can the instructor can do?}

Reframe problems to be user-centered

Have students conduct primary research (interviews, surveys, etc.) with their users

Experience things first hand: get students out into the field on site visits

Collaboratively create classroom discussion guidelines based on respect

\section{Why is this helpful?}

Projects which quickly converge on ideas without evolving those ideas past the initial design solution are often lacking in empathy with the end-user of that product or service or experience. It is vital to ambiguous projects that empathy is scaffolded throughout the project. By encouraging empathy, the students also are better able to recognize when they might be getting too 'attached' to their own design idea, rather than fully understanding the entirety of their project goals.

\section{- REFLECT}

What can the instructor can do?

Give students time to reflect on their experiences (both during and after the project)

Have students share their experiences with others outside of their discipline

Stay current: instructors should adapt and evolve coursework to reflect current problems and opportunities in their own communities and beyond 


\begin{abstract}
Why is this helpful?
Encouraging and even requiring students to reflect on their experiences can help students understand their own perspective and biases toward project solutions or goals. It also allows the student to slow down and pause and think about other avenues or populations they might not be serving or addressing. Reflection can also have a supporting role to other framework threads by encouraging a deeper dive and understanding of empathy and collaboration.
\end{abstract}

The manner in which pedagogy is structured can help to encourage students to think broadly about potential solutions, and mitigate the students' desire to jump to conclusions too quickly. Getting the students to understand the 'wickedness' of social problems and/or big tasks can often overwhelm them. By encouraging (and embracing) these actions throughout the projects and classroom experiences, the instructor can be prepared to help the students manage and acknowledge the unknown quality of many of our problems. Thus, helping the student prepare other methods of coping and managing -- or rather mitigating - their solutions around solvable issues.

\title{
Conclusion
}

As curricular needs change and evolve, the authors acknowledge the need for faculty and instructors to become more responsive to the current needs of their students. By providing a framework to utilize and acknowledge ambiguity in the classroom, it is the hope of the authors to promote a more flexible mechanism to update and adjust existing curricula. By encouraging collaboration, expecting that the students will be overwhelmed, and acknowledging the 'wickedness' of the process, the instructor will be more prepared to deal with these wild topics and better able to prepare today's students for tomorrow's open-ended challenges. Additionally, having the students mitigate their solutions rather than fully solve them creates better opportunities for success. Finally, engaging in activities first-hand and reflecting on those experiences will allow students to explore empathy more fully and come to their projects with a more accurate user-centered solution. Allowing engineering and design students to iterate through problems of a 'wicked' and open-ended nature will create professionals more comfortable with ambiguity — and thus, success. 


\section{References}

${ }^{1}$ Kelley, D. and Kelley, T. Creative Confidence. New York: Crown Business 2013.

${ }^{2}$ Gill, C., and Graell, M., “Teaching Design Thinking: Evolution of a Teaching Collaboration Across Disciplinary, Academic, and Cultural Boundaries." In Conference Proceedings, International Conference on Engineering and Product Design Education, 2016.

${ }^{3}$ Tjendra, Jeffrey, “The Origins of Design Thinking.” Wired Magazine. April, 2014 https://www.wired.com/insights/2014/04/origins-design-thinking/

${ }^{4}$ Brown, T. Change By Design. New York: HarperCollins Publishers, 2009.

${ }^{5}$ IDEO, The Field Guide to Human-Centered Design. San Francisco: IDEO, 2015

${ }^{6}$ Crick, Francis. "Oregon University Pauling Symposium: The Impact of Linus Pauling." http://oregonstate.edu/dept/Special_Collections/subpages/ahp/1995symposium/crick.html

7 "Defining the Architect's Basic Services." AIA. http://www.aia.org/aiaucmp/groups/secure/documents/pdf/aiap026834.pdf

${ }^{8}$ Milton and Rodgers, Product Design. London: Laurence King 2011. http://proquest.safaribooksonline.com/book/product-design/9781856697514

${ }^{9}$ Benzenberg, Elizabeth. "Exploring Design Process Evolution in Architecture and Interior Design Firms." Electronic Thesis, Ohio State University, 2011. OhioLINK Electronic Theses and Dissertations Center.

${ }^{10}$ Sanders, E. B.-N., and Stappers, P.J. “Co-Creation and the New landscapes of Design.” CoDesign: International Journal of CoCreation in Design and the Arts 4.1 (2008).

11 “Criteria for Accrediting Engineering Programs 2016-2017." ABET . http://www.abet.org/accreditation/accreditation-criteria/criteria-for-accrediting-engineering-programs2016-2017/

${ }^{12}$ Pahl, G., Beitz, W. Feldhusen, J., Grote, K.H., Engineering Design: A Systematic Approach. 3rd ed. Translated by Blessing, Luciënne, and Wallace, Ken. London: Springer-Verlag Ltd, 2007.

${ }^{13}$ Kamrani, Ali K., Nasr, Emad Abouel. Engineering Design and Rapid Prototyping. New York: Springer Science+Business Media, LLC, 2010.

${ }^{14}$ Cather, Harry, Morris, Richard, Philip, Mathew and Rose, Chris. Design Engineering. Oxford: Elsevier Ltd., 2001. http://proquest.safaribooksonline.com/book/engineering/9780080477114

${ }^{15}$ Eppinger, S., Ulrich, K. Product Design \& Development. 6th ed. New York: McGraw-Hill Education, 2015

${ }^{16}$ Chan,P., Melsop, S. and Sanders, E. B.-N. "Re-Envisioning a Design Curriculum.” In Conference Proceedings, DesignEd Asia Conference 2010. 
${ }^{17}$ Camerer, C. and Weber, M. J., "Recent Developments in modeling Preferences: Uncertainty and Ambiguity." Journal of Risk and Uncertainty 5. (1992) 325-370.

${ }^{18}$ Ellsberg, D. "Risk, Ambiguity, and the Savage Axioms." The Quarterly Journal of Economics 75.4, (1961): 643-669.

${ }^{19}$ Rittel, Horst, and Webber, Melvin. "Dilemmas in a General Theory of Planning". Policy Sciences 4, (1973): 155-169.

${ }^{20}$ J. Mendel. and Yaeger, "Knowledge Visualization in Design Practice: Exploring the Power of Knowledge Visualization in Problem Solving." Parsons Journal for Information Mapping, (2010). 